\section{Clear and Convincing Evidence}

Robert L. Heilbronner

Chicago Neuropsychology Group, Chicago, IL, USA

\section{Definition}

The burden of proof is the obligation to shift the assumed conclusion away from an oppositional opinion to one's own position: it may only be fulfilled by evidence. Under the Latin maxim, necessitas probandi incumbit ei qui agit, the general rule is that "the necessity of proof lies with he who complains." The burden of proof, therefore, usually lies with the party making the claim. The exception to this rule is when a prima facie case has been made. He who does not carry the burden of proof carries the benefit of assumption, meaning he needs no evidence to support his claim. Fulfilling the burden of proof effectively captures the benefit of assumption, passing the burden of proof off to another party. Clear and convincing evidence is a burden of proof required of a plaintiff for him to win the lawsuit. This standard is higher than mere preponderance of the evidence. Proof of fraud, for example, usually requires clear and convincing evidence. Clear and convincing evidence is the higher level of burden of persuasion and is most often employed in civil litigation. To prove something by "clear and convincing evidence," the party with the burden of proof must convince the trier of fact that it is substantially more likely than not that the thing is in fact true. This is a lesser requirement than "proof beyond a reasonable doubt," which requires that the trier of fact be close to certain of the truth of the matter asserted, but a stricter requirement than proof by "preponderance of the evidence," which merely requires that the matter asserted seems more likely true than not.

\section{Cross-References}

Beyond Reasonable Doubt

Burden of Proof

$\checkmark$ Preponderance of Evidence

\section{References and Readings}

Melton, G. B., Petrila, J., Poythress, N. G., \& Slobogin, C. (2007). Psychological evaluations for the courts: A handbook for mental health professionals and lawyers (3rd ed.). New York: Guilford Press. 